\title{
Using Resistivity Measurements to Determine Anisotropy in Soil and Weathered Rock
}

\author{
Sandra Soto-Cabán \\ Department of Physics and Engineering \\ Muskingum University \\ New Concord, OH, USA \\ ssoto@muskingum.edu
}

\author{
Eric Law \\ Department of Geology \\ Muskingum University \\ New Concord, OH, USA \\ ericlaw@muskingum.edu
}

\begin{abstract}
This study uses electrical resistivity measurements of soils and weathered rock to perform a fast and reliable evaluation of field anisotropy. Two test sites at New Concord, Ohio were used for the study. These sites are characterized by different landform and slightly east dipping limestone and siltstone formations of Pennsylvanian age. The measured resistivity ranged from $19 \Omega \cdot \mathrm{m}$ to $100 \Omega \cdot \mathrm{m}$, and varied with depth, landform, and season. The anisotropy was determined by a comparison of resistance values along the directions of strike and the dip. Measurements showed that the orientation of electrical anisotropy in the shallow ground may vary due to fluid connection, which is determined by the pore geometry in soil and rock, as well as by the direction of fluid movement. Results from this study indicated that a portable electrical resistivity meter is sensitive and reliable enough to be used for shallow ground fluid monitoring.
\end{abstract}

Keywords- soil resistivity; resistance; soil anisotropy; resistivity measurements

\section{INTRODUCTION}

The hydrological anisotropy of soil and weathered rock beneath it is an important issue in many studies and applications. While the change of anisotropy may be expected in a vertical soil profile and rock stratification, the change of anisotropy along a horizontal layer of soil or rock is usually much less obvious. However, the horizontal variation of anisotropy is also a significant feature and has been demonstrated in several studies e.g. [1-5].

Measuring the electrical resistivity of the ground is a nondisturbing geophysical method that is commonly used to explore the properties of soil and rock. It has been extensively used in various environmental and engineering studies [6-9]. In [9], the authors demonstrated that if some ground variables can be monitored, then the on-field electric resistivity method is a good alternative to other much more expensive and difficult methods for quantitatively monitoring the moisture distribution of ground shallower than 10 meters. This method can be used to identify the direction of horizontal anisotropy in the soil by measuring and comparing the resistivity along profiles of different directions at the same locality. Moisture content is one of the major factors in determining ground resistivity $[9,10]$.
Ground moisture condition depends on several other factors, such as weather, season, types of soil and rock [9, 11, 12]. As a consequence, the value of resistivity, particularly for shallow ground, may change quickly and significantly with time and ground conditions. Since the anisotropy is expressed by the ratio of resistivity values along different directions, common factors that will affect resistivity, such as moisture content, weather conditions, groundwater chemistry, and time will be cancelled out, and the difference on the ratios will only reflect the variation of controlling factors.

The purpose of this study is to use a portable resistivity meter to take measurements of soil resistivity, and to determine the nature of anisotropy of shallow ground up to a depth of 20 feet. Measurements of ground resistivity and anisotropy are described and interpreted.

\section{Methodology}

\section{A. Resistivity Meter and Measurements}

Soil resistivity testing was performed using the 4-point Wenner Array Method [13]. This method is the most used test method to measure the resistivity of soil for electrical grounding design. The Wenner array, illustrated in Figure 1, consists of a line of four equally spaced electrodes. Current is injected through the outer electrodes $\mathrm{C}_{1}$ and $\mathrm{C}_{2}$, and potential is measured between the inner electrodes $\mathrm{P}_{1}$ and $\mathrm{P}_{2}$. The resistivity meter used is Model H-4385 made by Humboldt MFGC [14]. Based on [13], the pin separation should be approximately 20 times larger than the pin depth in the soil. Pin depth is important to properly measure the resistivity of deeper ground. The resistivity of soil using the Wenner array can be calculated using

$$
\rho=2 \pi a \frac{V}{I}
$$

where $a$ is the electrode separation, $V$ is the difference in potential between $\mathrm{P}_{1}$ and $\mathrm{P}_{2}$, and $I$ is the current flowing between $\mathrm{C}_{1}$ and $\mathrm{C}_{2}$. Using Ohm's Law, $V / I=R$. The value of $R$ is given by the meter and thus $\rho$ can be calculated using (1). 


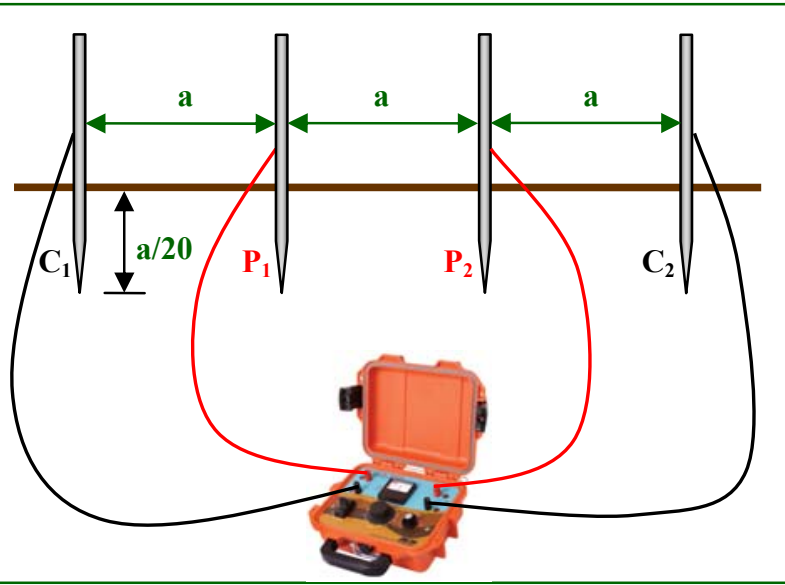

Fig. 1. Wenner array. The resistivity meter used is Model H-4385 made by Humboldt MFGC

\section{B. Testing Sites}

Measurements of soil resistivity were taken at two different locations in New Concord, Ohio. Site 1 is a small flat area on the top of a hill. Site 2 is a lithology controlled slope. The slope surface is tilted $30^{\circ}$ toward East. The soil profile at both sites received minimum disturbance. However, at site 1 , there was an east-west oriented, 5 feet deep utility trench, which was dug and backfilled about 12 years ago.

Soils over the test area are derived from rocks of the Upper Pennsylvanian Conemaugh formation. In general, the bottom of site 2 is not deeper than 5 feet. The bedding of bed rock has a NS strike with a few degree dip toward the east. The strata include the Ames Limestone and siltstone layers above and below the limestone. The Ames Limestone is a 3-feet thick fresh crystalline packstone, which has no appreciable permeability. However, the slab shape limestone has been weathered through along joints and becomes isolated slabs of 1 to 5 meters in diameter. At both sites, the limestone is located between weathered siltstone layers.

Soil resistivity in both sites was measured using the 1D Wenner array along both NS and EW direction of selected locality. Resistivity at site 1 was measured in two different seasons, summer and winter, to acquire seasonal contrast. For measurements taken during the summer, additional readings were taken along profiles of $\mathrm{N} 45 \mathrm{E}$ and $\mathrm{N} 45 \mathrm{~W}$. At each array, the average resistance to the depths of 10, 15 and 20 feet was measured. Ground conditions of both sites were seasonally dry in the summer. In winter, the ground was cold and moist, but not frozen.

\section{RESULTS}

\section{A. Resistivity}

The results of resistivity values calculated from the measured resistances in site 1 during winter are summarized in Figures 2 and 3.

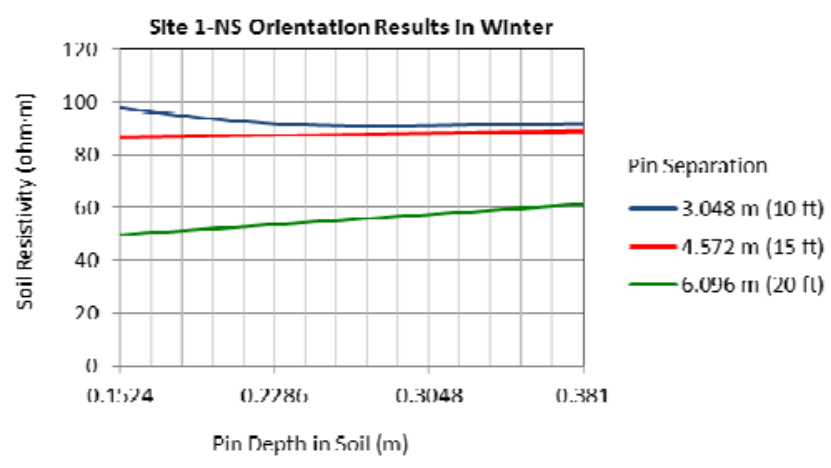

Fig. 2. Resistivity values in site 1 measured in the NS direction in winter.

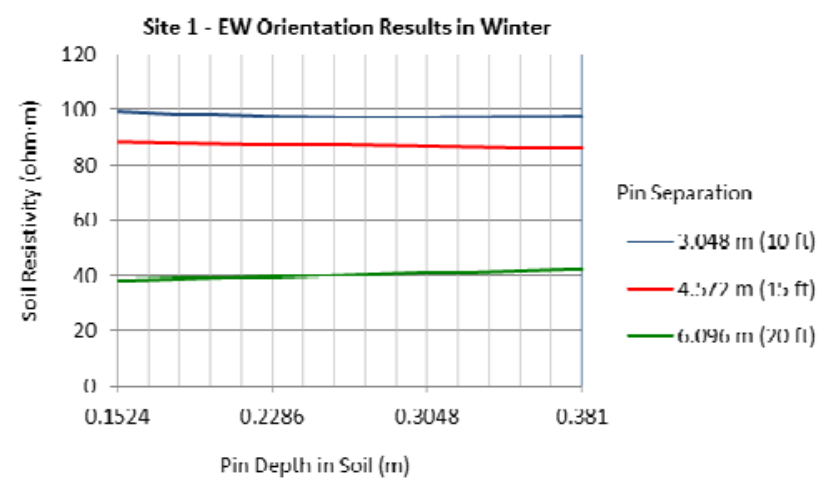

Fig. 3. Resistivity values in site 1 measured in the EW direction in winter.

During the summer months, resistance measurements where taken in the NS, EW, and N45E directions. Pin separations of $1.524 \mathrm{~m}$ (5 feet) and $3.048 \mathrm{~m}$ (10 feet) where used. Results are presented in Figure 4.

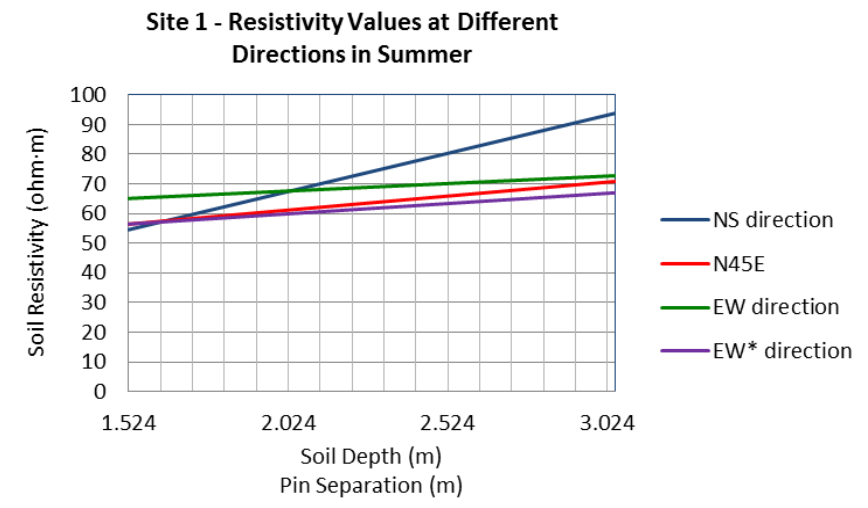

Fig. 4. Resistivity values in site 1 measured in different directions in summer. The $\mathrm{EW}^{*}$ direction means that measurements were taken where the profile runs along a dug and refilled utility trench of 4 feet deep.

The resistivity at site 1 varied from $40 \Omega \cdot \mathrm{m}$ to $100 \Omega \cdot \mathrm{m}$. This range of value is at the low end of common fresh sedimentary rocks reported in [15]. Considering that all the measured material is soil and weathered rock, resistivity at the low end of normal range was expected. 
A $1.524 \mathrm{~m}$ ( 5 feet) deep utility trench was dug and back filled at site 1 in 2001. A sequence of measurements were taken around this trench and are identified in Figure 4 as the EW* direction. The resistivity on the trench profile at $1.524 \mathrm{~m}(5$ feet) and $3.048 \mathrm{~m}$ (10 feet) depth was measured. To provide a comparison, resistivity was also measured along the same direction, but with a $0.9144 \mathrm{~m}$ ( 3 feet) offset to the undisturbed ground (EW direction in Figure 4). The data shows that resistivity along the disturbed ground is $8 \Omega \cdot \mathrm{m}$ to $6 \Omega \cdot \mathrm{m}$, lower than that of the undisturbed ground.

Measurements in site 2 where taken during the summer. Soil in site 2 is similar to the soil in site 1 but it has a sloped surface tilted $30^{\circ}$ toward East. The measured values of resistivity ranged from $19 \Omega \cdot \mathrm{m}$ to $28 \Omega \cdot \mathrm{m}$, as shown in Figure 5 . The data have narrower variation and measured resistivity values are significantly lower than the measured resistivity values in site 1 . These values were taken during the dry season, but the lower resistivity suggests that the ground probably has higher moisture content. Consider that site 2 is a $30^{\circ}$ eastfacing slope, and is where shallow groundwater accumulates and exits. The significantly lower resistivity reflects the effect of a slope on surface moisture.

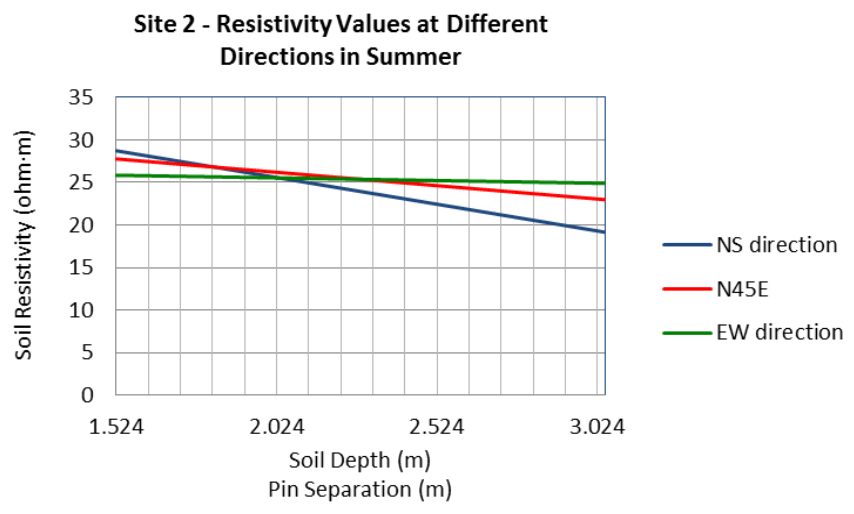

Fig. 5. Resistivity values in site 2 measured in different directions in summer.

Fresh carbonate rock has resistivity around $300 \Omega \cdot \mathrm{m}[15]$ which is much higher than any measured resistivity in this study. The shallow dense Ames Limestone layer in the studied area does not raise the resistivity values beyond the range of the surrounding weathered siltstones. This could imply that the limestone is significantly fractured and therefore, it does not hinder the passage of electric current. This interpretation was confirmed by the observation on many constructions made in the neighborhood of the study area. The excavations showed that the limestone layer has been weathered through and is broken into slabs approximately 2 by 3 meters or smaller.

\section{B. Anisotropy}

In this study, the degree of anisotropy is evaluated by comparing the resistivity along the strike of the formation to that along the dip of the formation. The attitude of rock formation is the same at both sites, and has strike approximately in NS and dip a few degrees toward east. If the ratio is within $\pm 10 \%$ of 1 , then it is taken as a lack of anisotropy. The larger the ratio (i.e. larger than 1), the stronger the anisotropy. Absolute values of degree of anisotropy were not assigned to the resistivity ratios. When the activity ratio is significantly larger than 1 , it means that the resistivity along the EW profile is lower. This is interpreted as that the EW direction has better moisture connectivity of pore fluids. It implies that either the pore spaces are better connected or the moisture is moving across the pore spaces along the EW direction. For site 1, the resistivity ratios are presented in Table I.

TABLE I. RESISTIVITY RATIOS

\begin{tabular}{|c|c|c|}
\hline Site 1 (NS/EW) & Shallow $(<\mathbf{3 . 0 4 8 ~} \mathbf{~ m ; ~ 1 0 ~ f t ) ~}$ & Deep $(\geq \mathbf{3 . 0 4 8 ~} \mathbf{~ m ; ~ 1 0 ~ f t )}$ \\
\hline Winter & $0.94-1.04$ & $1.45-2.00$ \\
\hline Summer & 0.84 & 1.29 \\
\hline
\end{tabular}

The data show that when the pin separation is shorter than $6.096 \mathrm{~m}$ (20 feet), there is a lack of anisotropy down to 3.048$4.572 \mathrm{~m}$ (10-15 feet) deep at site 1 during the winter time. When the pin separation is extended to $6.096 \mathrm{~m}$ (20 feet), resistivity became lower, but the degree of anisotropy significantly increased. Higher resistivity was shown along the NS direction. This suggested that ground moisture became higher in the deeper ground, which reduced the resistivity. Also, the moisture connection in pore spaces is better along the EW direction, which is the direction of the formation dip. This feature is interpreted as that in the winter (wet) season, the moisture in the shallow ground is stagnant, but the moisture is moving toward east in the deeper ground. In the summer time, the degree of anisotropy at the shallow ground becomes significant. This is shown in Table II.

TABLE II. RESISTIVITY RATIOS IN SUMMER

\begin{tabular}{|c|c|c|}
\hline Summer (NS/EW) & Shallow & Deep \\
\hline Site 1 & 0.84 & 1.29 \\
\hline Site 2 & 1.11 & 0.77 \\
\hline
\end{tabular}

The data further indicates that for both sites in the winter and summer seasons, the anisotropy remained similar in direction at the deeper ground. The anisotropy at the shallow ground changed from insignificant in winter to EW enhanced, which is the opposite direction to that in the deeper ground, during the summer time.

At site 1, the anisotropy shown in the summer dry season in the shallow ground indicates a better pore fluid connection along the direction of strike, which is the NS direction. This interpretation agreess with $[16,17]$. During the wetter winter season, more abundant pore fluid obscured this trend and made the shallow ground seems isotropic. On the other hand, the moisture in the deeper ground is always moving toward the East. This shows the EW anisotropy in both the wetter winter and the drier summer for the deeper ground. The higher amount of flow makes a stronger anisotropy during the winter time. Also, the shallow ground along the trench is also lacking anisotropy (0.97 ratio), but the undisturbed ground shows significant anisotropy (0.84). These data suggest that the 
material along the disturbed trench is more porous and homogenous than that on the undisturbed ground.

At site 2, in addition to the significantly lower resistivity, the anisotropy is also significant in both shallow and deep grounds. The direction of anisotropy is not only opposite in direction between the shallow ground and the deeper ground, but is opposite to that in site 1 at the same time (Table II). In the shallow ground, which is less than $1.524 \mathrm{~m}$ ( 5 feet) deep, resistivity is lower along the direction of dip (EW). At ground deeper than $3.048 \mathrm{~m}$ (10 feet), resistivity becomes lower along the direction of strike (NS). This switch of anisotropy suggests that ground moisture is moving down the slope (and the dip) near surface, but is lacking movement in deeper ground.

\section{CONCLUSIONS}

This study measured the resistivity of soil and underlay weathered rock down to $6.096 \mathrm{~m}$ (20 feet) deep. It included the unsaturated zone and the shallow saturated zone. The measurements were taken along the strike and the dip directions of the rock formation. The ratio of resistivity along the two directions filtered out common factors that change the value of resistivity, but preserved the factors that affect the anisotropy. The abundance of moisture in the unsaturated zone and the direction of moisture movement in the saturated zone were two major factors.

Measured data suggested that the electrical resistivity and anisotropy of shallow ground, less than $6.096 \mathrm{~m}$ (20 feet) deep, are easily changed by conditions of depth, landform, geological structure and weather. Resistivity is also sensitive to the soil and rock conditions. The best illustration of the sensitivity is the comparison of resistivity along a 12-year old utility trench and its adjacent undisturbed ground. As a result, the method used in this study is useful in indicating minute variations of moisture conditions due to various reasons, and it can serve as a quick field method to check contemporary hydrological condition of shallow ground.

While the resistivity at site 1 is several times higher than that at site 2, the degree of anisotropy is approximately the same, even though the direction of anisotropy got reversed with depth during the time of testing, since the anisotropy is measured by the ratio of resistivity. Due to the difference of landform which affected the direction of moisture flow, the variation of anisotropy at the two sites more likely reflects the characteristics of pore geometry and the movement of pore fluid.

This study shows that the anisotropy is clearly indicated along the bedding plane. Resistivity data show that when the pore fluid in soil and shallow rocks is stagnant, the moisture in the pore space is better connected along the strike direction than that along the dip direction. This result is in agreement with the study of pore space geometry [18-20]. However, when the pore fluid starts to move due to either pore saturation or hydraulic pressure from a slope, it will produce a better electric conductivity along the direction of water movement. In this case, it is the dip direction that has a key role. Since the degree of water saturation in the unsaturated zone is easily modified by the weather and season, the direction of electrical anisotropy may also be changed when moisture conditions are changed.

\section{REFERENCES}

[1] A. Anandarajah, N. Kuganenthira, "Some aspects of fabric anisotropy of soil", Geotechnique, Vol. 45, No. 1, pp. 69-81, 1995

[2] M. Bała, "Evaluation of electric parameters of anisotropic sandy-shaly miocene formations on the basis of resistivity logs", Acta Geophysica Vol. 59, No. 5, pp. 954-966, 2011

[3] R. P. Chapuis, D. E. Gill, "Hydraulic anisotropy of homogeneous soils and rocks: Influence of the densification process", Bulletin of the International Association of Engineering Geology, Vol. 39, No. 1, pp. 75-86, 1989

[4] J. L. Collins, M. E. Everett, B. Johnson, "Detection of near-surface horizontal anisotropy in a weathered metamorphic schist at Llano Uplift (Texas) by transient electromagnetic induction", Physics of the Earth and Planetary Interiors, Vol. 158, No. 2-4, pp. 159-173, 2006

[5] C. T. Petersen, A. Trautner, S. Hansen "Spatio-temporal variation of anisotropy of saturated hydraulic conductivity in a tilled sandy loam soil", Soil and Tillage Research, Vol. 100, No. 1-2, pp. 108-113, 2008

[6] V. C. Goyal, S. Niwas, P. K. Gupta, "Theoretical evaluation of modified Wenner array for shallow resistivity exploration", Ground Water, Vol. 29, No. 4, pp. 582-586, 1991

[7] J. W. Lane Jr, F. P. Haeni, W. M. Watson, "Use of square-array directcurrent resistivity method to detect fractures in crystalline bedrock in New Hampshire", Groundwater, Vol. 33, No. 3, pp. 476-485, 1995

[8] M. U. Osakuni, T. K. S. Abam, "Shallow resistivity measurement for cathodic protection of pipelines in the Niger Delta", Environmental Geology, Vol. 45, No. 6, pp. 747-752, 2004

[9] B. F. Schwartz, M. E. Schreiber, T. Yan "Quantifying field-scale soil moisture using electrical resistivity imaging", Journal of Hydrology, Vol. 362, No. 3-4, pp. 234-246, 2008

[10] L. Chen, Z. Yin, P. Zhang "Relationship of resistivity with water content and fissures of unsaturated expansive soils", Journal of China University of Mining and Technology, Vol. 17, No. 4, pp. 537-540, 2007

[11] Z. S. Abu-Hassanein, C. H. Benson, L. R. Blotz, "Electrical resistivity of compacted clays", Journal of Geotechnical Engineering Vol. 122, No. 5, pp. 397-406, 1996

[12] V. A. Rinaldi, G. A. Cuestas, "Ohmic conductivity of a compacted silty clay", Journal of Geotechnical and Geoenvironmental Engineering, Vol. 128, No. 10, pp. 824-835, 2002

[13] F. Wenner, "A Method of Measuring Earth Resistivity", Bulletin of the Bureau of Standards, Vol. 12, pp. 469-478, 1916

[14] Humboldt Manufacturing Company (), "Resistivity-Meter", http://www.humboldtmfg.com/resistivity_meter.html, 2013

[15] B. S. Badmus, E. A. Ayolabi, J. A. Olowofela, S. A. Adisa, T. O. Oyekunle "Current variation in electrical resistivity probing using Wenner and Schlumberger arrays in a basement terrain", J.ournal of Geophysics and Engineering, Vol. 2, No. 2, pp. 118-125, 2005

[16] P. Domnesteanu, C. McCann, J. Sothcott, "Velocity anisotropy and attenuation of shale in under-and overpressured conditions", Geophysical Prospecting, Vol. 50, No. 5, pp. 487-503, 2002

[17] M. L. Stewart, A. L. Ward, D. R. Rector, "A study of pore geometry effects on anisotropy in hydraulic permeability using the latticeBoltzmann method", Advances in Water Resources, Vol. 29, No. 9, pp. 1328-1340, 2006

[18] C. A. Grattoni, R. A. Dawe, "Anisotropy in pore structure of porous media”, Powder Technology, Vol. 85, No. 2, pp. 143-151, 1995

[19] E. Kuusela, J. Lahtinen, T. Ala-Nissila, "Sedimentation dynamics of spherical particles in confined geometries", Physical Review E, Vol. 69, No. 6, pp. 066310-1-066310-9, 2004

[20] L. Esteban, Y. Geraud, J.L. Bouchez, "Pore network connectivity anisotropy in Jurassic argillite specimens from eastern Paris Basin (France)", Physics and Chemistry of the Earth, Vol. 32, No. 1-7, pp. $161-169,2007$ 


\section{AUTHORS PROFILE}

Dr. Sandra Soto-Cabán received her Bachelor's and Master's degrees in Electrical Engineering from University of Puerto Rico, Mayagüez Campus, and her Ph.D. degree in Electrical Engineering from Michigan State University, East Lansing, MI. Currently she is an Assistant Professor of Engineering in the Department of Physics and Engineering at Muskingum University, New Concord, Ohio, USA. Dr. Soto-Cabán is a senior member of the Institute of Electrical and Electronics Engineers (IEEE) and a member of the American Society of Engineering Education (ASEE). She is also a member of the engineering honor societies Tau Beta Pi and Eta Kappa Nu.
Her research interests include electromagnetic simulation of underground contaminants, material characterization, and engineering education.

Dr. Eric Law received his Ph.D. degree in Geology in 1984 from Case Western Reserve University, Cleveland, Ohio, USA. Currently works as an Associate Professor in the Geology Department of Muskingum University at New Concord, Ohio. His most recent research is focused on the role of mechanical erosion on limestone. 